\title{
Sediment Quality Assessment for Heavy Metal Contamination in the Dongzhai Harbor (Hainan Island, China) with Pollution Indice Approach
}

\author{
Jie Yang ${ }^{1,2, \dagger}$, Baoxue Zhang ${ }^{1, \dagger}$, Xiaojuan Peng ${ }^{1, *}$, Hua Wang ${ }^{1}$, Zhihang $\mathrm{Li}^{1}$, Weixu Cai ${ }^{1}$ and Hongda \\ Fang $^{1}$ \\ ${ }^{1}$ South China Sea Marine Environment Monitoring Center, SOA, Guangzhou, 510915, China \\ ${ }^{2}$ School of Earth Sciences and engineering geology, Guangdong Provincial Key Laboratory of Geological Processes \\ and Mineral Resource Exploration, Sun Yat-sen University, Guangzhou, 510275, China
}

\begin{abstract}
This study concerns the distribution and potential sources of elevated heavy metal concentrations $(\mathrm{Cu}, \mathrm{Zn}, \mathrm{Pb}$, $\mathrm{Cd}, \mathrm{As}$ ) in surface sediments of the Dongzhai Harbor, Hainan Island,a national important mangrove ecosystem protection area.It was found that the pollution of As may occur occasional biological effect by numerical Sediment Quality Guidelines. Further, Geoaccumulation indices $\left(\mathrm{I}_{\text {geo }}\right)$ suggest there are serious pollution levels of As at all five stations. Spatial distribution of ecotoxicological index and pollution load index suggested that most of the surface sediments have a $9 \%$ probability of being toxic and the potential ecological risk zone appear in northern and southern of Dongzhai Harbor. Correlation analysis, principal component analysis, and cluster analysis showed that these metals primarily originate from natural sources. As and $\mathrm{Pb}$ resulted primarily from aquaculture, and combustion of gasoline and diesel fuel by ships. The present study provides a baseline record of heavy metals in mangrove surface sediments on the Dongzhai Harbor, and provide a useful aid for sustainable marine management in this region.
\end{abstract}

Keywords: Heavy metal, sediment, risk assessment, Dongzhai harbor, Hainan Island.

\section{INTRODUCTION}

Heavy metal contamination in aquatic environment has drawn particular attentions due to their toxicity, persistence and biological accumulation (Jiang et al., 2012). Heavy metals have low solubility and primarily get absorbed and accumulated on bottom sediments. Bottom marine sediments are sensitive indicators for monitoring pollutants as they act as a sink and a carrier for contaminations in aquatic environment (Cao et al., 2014). The study of bottom bay sediments plays an important role for their longer residence time, and the role is called "the record of history" (Mackay, 2001). Thus, spatial surveys of metal concentrations in the sediments are useful to assess pollution in the marine environment and to provide basic information for the judgment of environmental health risks.

The Mangrove ecosystems are unique coastal estuarine systems confined to the tropical and subtropical regions (Bayen, 2012). These zones are dominated by mangrove plants, which are highly productive and play a vital role, both as the major primary producers in estuarine ecosystems and meanwhile, it is the most endangered one (FernándezCadena et al., 2014). Mangrove becomes the source and collection area of heavy metals usually, belonging to the

-Address correspondence to this author at No. 135, at Xingang Xi Road, Guangzhou, 510275, P. R. China;

Tel/Fax: +86 -020-84191002; E-mail: cllzsu@163.com;

$\dagger$ These authors contributed equally to this work. connection of ocean and land (Tam et al., 2000). Therefore, mangrove ecosystem is recently a topic of much discussion. Mangrove of Dongzhai Harbor in Hainan is a national important mangrove ecosystem protection area. In this region, there are lots of works about heavy metal distribution. However, no detailed study has so far been conducted especially on ecological risk assessment for heavy metals contamination in depositional environment. Therefore, the present investigation aimed to study the levels of metals $(\mathrm{Cu}, \mathrm{Zn}, \mathrm{Pb}$, Cd, As) in sediment samples of Dongzhai Harbor, primarily to generate data on evaluate the degree of contamination and potential ecological risk and offer some theoretical significance and practical value for mangrove ecosystem protection.

\section{MATERIALS AND METHODS}

A total of 5 surface sediment $(0-5 \mathrm{~cm})$ samples were collected by a grab sampler using a small vessel in July 2010 (Fig. 1). All samples were stored in refrigerators at $4^{\circ} \mathrm{C}$ until analysis. All samples were oven-dried at $45{ }^{\circ} \mathrm{C}$ for $24 \mathrm{~h}$. After removing the gravels and large debris, about $20 \mathrm{~g}$ of the subsamples were ground with agate mortar and pestle, and then to pass a $0.125 \mathrm{~mm}$ sieve and stored in clean plastic bags at room temperature prior to analyses. The concentrations of $\mathrm{Cu}, \mathrm{Pb}, \mathrm{Zn}, \mathrm{Cd}$ and As were all detected by means of inductively coupled plasma-mass spectrometry (ICP-MAS). Blanks and China Stream Sediment Reference Materials (GBW07345, GSD9, and GSD4) were included in the anal- 

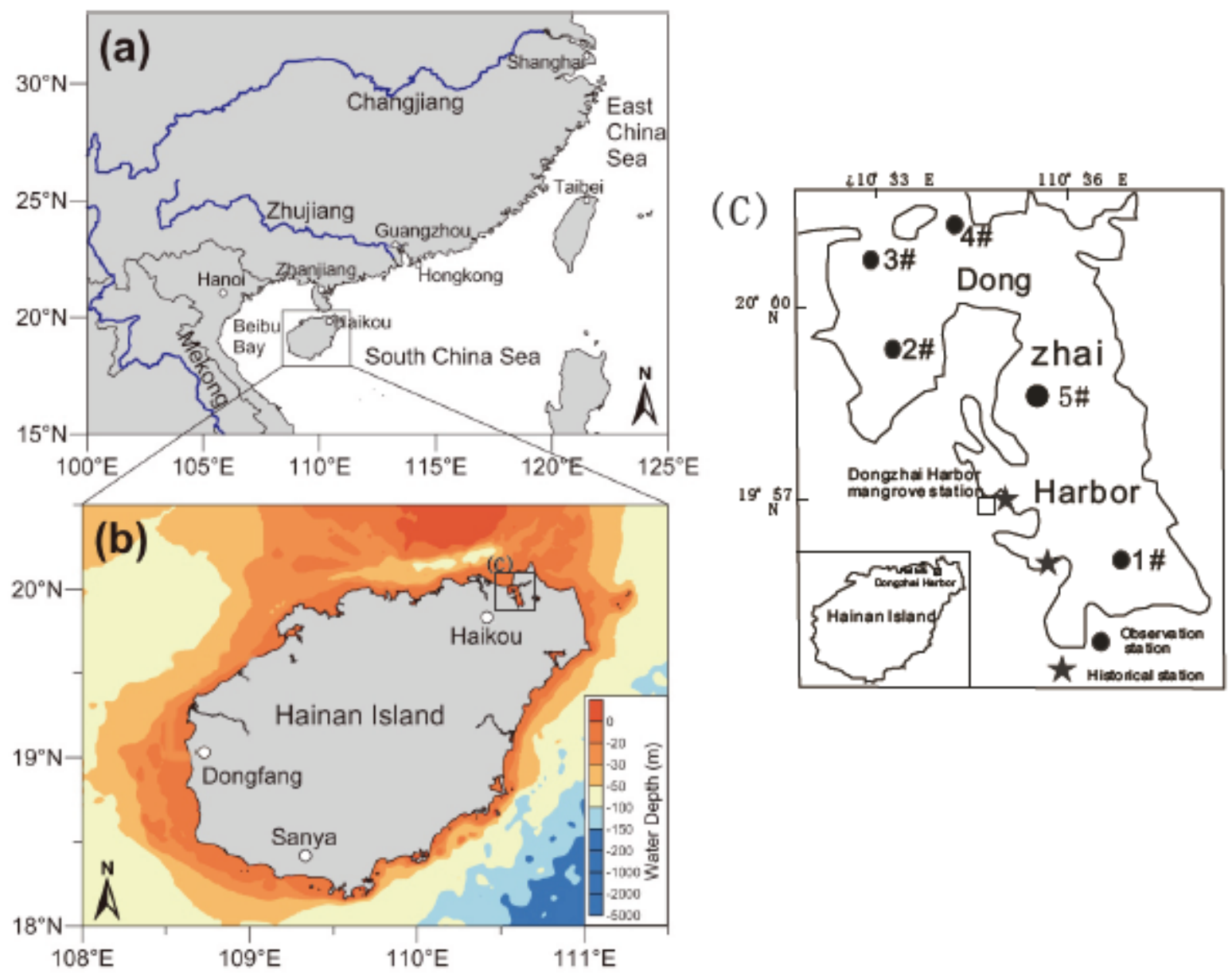

Fig. (1). Map of sampling stations.

yses for data QA/QC. Replicated samples were measured with a variation of $<10 \%$.

\section{RESULTS AND DISCUSSION}

As shown in Table 1, the variation of different metals in sediments from Dongzhai Harbor and several indices are listed. The analysis of the data depicted an order of metals accumulation in sediment that was $\mathrm{Zn}>\mathrm{Pb}>\mathrm{Cu}>\mathrm{As}>\mathrm{Cd}$. The data indicated that $\mathrm{Zn}$ was maximally accumulated in the sediments whereas $\mathrm{Cd}$ get least accumulation. The metal concentrations were compared to Primary Marine Sediment Quality criteria (GB 18668-2002) by State Environmental Protection Administration of China (SEPA, 2002). The average concentrations of the metals were far lower than the SQG values except for As. Most of them, including $\mathrm{Zn}, \mathrm{Pb}$, $\mathrm{Cu}$ and $\mathrm{Cd}$, were close to background values while As surpass. The major contribution of anthropogenic metals in a marine coastal area is of terrestrial origin, i.e. from urban development and other human activities near the mangrove (Qiu et al., 2011). The low metal concentration in Dongzhai Harbor firstly due to the feature on absorb, deposit and settle down metals in mangrove ecosystems and also due to the less developed industry and a relatively low human population.
Effects range low (ERL) and effects range median (ERM) are SQGs developed to categorize the range of concentrations in sediment the effects of which are scarcely observed or predicted (below the ERL), occasionally observed (ERL-ERM), and frequently observed (above the ERM) (Long et al., 1990; Cao et al., 2015). Effects Range-Low (ERL) and Effects Range-Median (ERM) were the main parameters used to estimate the adverse biological effects of metals in the marine and estuary sediments and derived for the US National Oceanic and Atmospheric Administration (NOAA), with numerous types of modeling, laboratory and field studies performed on marine and estuarine sediments. Metal concentrations in sediments can be classified into three levels, namely rarely $(<\mathrm{ERL})$, occasionally (ERLERM) and frequently ( $\geq$ ERM) associated with adverse biological effects. Our results in Table 1 show that ERL was never exceeded but As in the study areas, and As concentrations were over ERL more than twice in almost five stations, which would likely not cause occasionally effects in the studied areas.

The pollution load index $(P L I)$ was introduced to evaluate the level of metal contamination. The PLI is determined as the $n$th root of the $n$ contamination factors $\left(C f_{\mathrm{n}}\right)$ multiplied together and calculated using the following equation: 
Table 1. Major element concentrations and marine sediment quality guidelines, expressed as (mg/kg) dry weight.

\begin{tabular}{|c|c|c|c|c|c|c|}
\hline Sample ID & $\mathbf{C u}$ & $\mathbf{Z n}$ & $\mathbf{P b}$ & Cd & As & References \\
\hline $1 \#$ & 4.80 & 50.52 & 13.90 & 0.001 & 18.43 & \multirow{3}{*}{ This study } \\
\hline $3 \#$ & 2.21 & 24.91 & 15.42 & 0.002 & 16.84 & \\
\hline $5 \#$ & 2.38 & 21.09 & 6.13 & 0.002 & 14.46 & \\
\hline \multicolumn{7}{|c|}{ Guidelines for metals contamination in sediment } \\
\hline $\mathrm{UCC}$ & 25 & 71 & 34 & 0.098 & 1.6 & Taylor, 1995 \\
\hline
\end{tabular}

UCC: average concentrations of the upper continental crust

$P L I=\left(C f_{1} \mathrm{x} C f_{2} \mathrm{x} C f_{3} \mathrm{x} \ldots C F_{\mathrm{n}}\right)^{1 / \mathrm{n}}$

The $C f$ for each metal is the ratio of the measured concentration in the sediment to the background value, which is classified into four grades for monitoring the pollution of one single metal over a certain period of time (Hakanson et al., 1980).

The PLI was applied to determine the integrated pollution status of the combined toxicant groups at the sampling stations. The $P L I$ value $>1$ indicates a polluted condition, while $P L I<1$ signifies no metal pollution(Tomlinson et al., 1980). The spatial map of PLI in Fig. (2) shows that the PLI results for all the stations ranged from 0.25 to 0.72 , and the highest $P L I$ value of 0.72 occurred at station S4, suggesting that our studied region was no metal pollution.

The mean ERM quotient is calculated using the following formula:

mean-ERM quotient $=\Sigma\left(C_{\mathrm{x}} / \mathrm{ERM}_{x}\right) / n$

where $C_{\mathrm{x}}$ is the measured concentration of the examined component $(x)$ in the sediment, ERM $x$ is the ERM for metal $x$, and $n$ is the number of metals. The mean- ERM quotients of less than or equal to 0.1 (low priority site) have a $9 \%$ probability of being toxic, quotients of 0.11-0.5 (mediumlow priority site) have a $21 \%$ probability, quotients of 0.51 1.5 (high-medium priority site) have a $49 \%$ probability, and quotients of greater than 1.50 have a $76 \%$ probability. Based on the mERM-Q data (Fig. 2), all the investigated stations had $\mathrm{mERM}-\mathrm{Q}<0.1$ (low priority site) varying within the range of $0.06-0.09$, and had a $9 \%$ probability of being toxic. Both the $P L I$ and mERM-Q revealed that the highest potential ecological risk zone was found in northern and southern of bay.

The geoaccumulation factor for 5 elements was calculated according to the following equation, where BEn is geochemical background values of heavy metals and $\mathrm{Cn}$ is content of the element in sediments (a measured value, meaning mass ratio).

$1_{\text {geo }}=\log _{2}[\mathrm{Cn} /(1.5 \mathrm{BEn})]$

The pollution classes, ranging from Class 0 ( $\mathrm{I}_{\mathrm{geo}} \leq 0$, unpolluted), to Class 6 ( $\mathrm{I}_{\mathrm{geo}}>5$, extremely polluted) proposed were used for this evaluation. The results in Table 2 are showed index of geo-accumulation $\left(1_{\mathrm{geo}}\right)$ of $\mathrm{Cu}, \mathrm{Zn}, \mathrm{Pb}, \mathrm{Cd}$ are low, however, that of As is 4 , meaning a serious pollution. Overall, index of geo-accumulation of heavy metal in mangrove wetland is a slightly higher than that in bottom sediments of Dongzhai Harbor, consistent with the results of the single factor evaluation. For further potential pollution sources analysis, the PCA was applied.

Pearson correlation and multivariate Principal Component Analysis (PCA) were performed on IBM SPSS 19.0 for Windows. The Pearson correlation analysis (CA) was used to evaluate the coefficients between all metals and biogenic elements. The logarithm-transformed data matrix was applied to the principal component analysis (PCA) to visualize potential pollution sources. Varimax rotation with Kalser normalization was chosen in PCA to maximize factor variance and to simplify the columns of the factor matrix. The Pearson correlation coefficient is significant for $\mathrm{Pb}-\mathrm{As}$, $\mathrm{Zn}-\mathrm{Cd}, \mathrm{Zn}-\mathrm{As}(\mathrm{p}<0.05)$ and $\mathrm{Cu}-\mathrm{Zn}, \mathrm{Cu}-\mathrm{Cd}(\mathrm{p}<0.01)$. These associations are obvious on the basis of pollution sources, indicating that these metals are closely related to each other and may have different anthropogenic or natural sources.

PCA was performed on the metal fractionation data, and the scores in the rotated principal component space are presented in Table 4. Two components were extracted which explain $85 \%$ of the total variance, and the eigenvalues $>1$. Almost selected metals were grouped together near the 

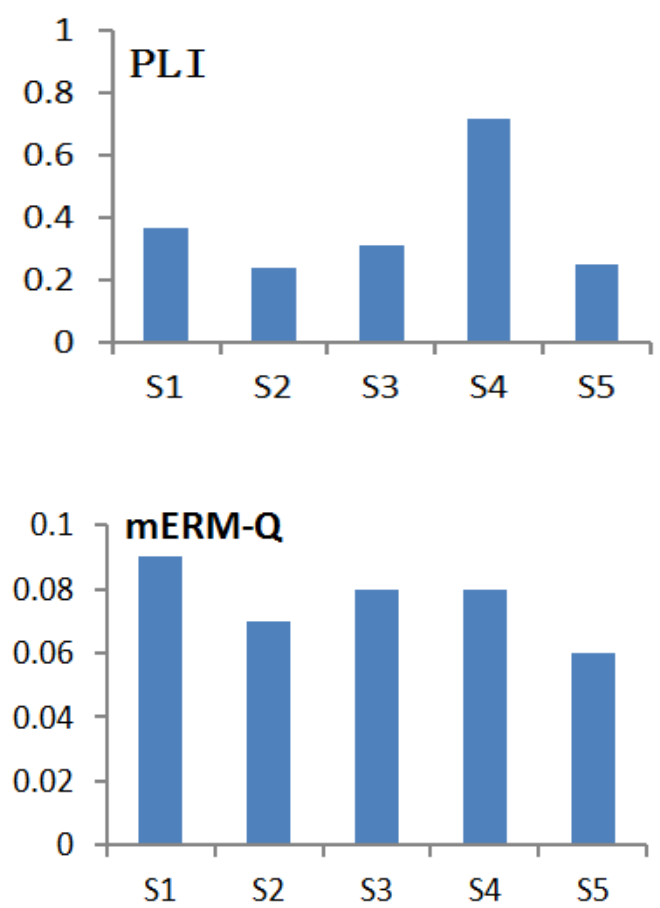

Fig. (2). The pollution load index (left) values and mERM-Q (right) values.

Table 2. Index of geo-accumulation $\left(l_{\text {geo }}\right)$ and the pollution grades of heavy metals.

\begin{tabular}{|c|c|c|c|c|c|c|c|c|c|c|c|c|}
\hline & \multicolumn{2}{|c|}{ S1\# } & \multicolumn{2}{|c|}{ S2\# } & \multicolumn{2}{|c|}{ S3\# } & \multicolumn{2}{|c|}{ S4\# } & \multicolumn{2}{|c|}{ S5\# } & \multicolumn{2}{|c|}{ wetland\# } \\
\hline & $\mathbf{l}_{\text {geo }}$ & level & $I_{\text {geo }}$ & level & $\mathbf{I}_{\mathrm{geo}}$ & level & $I_{\text {geo }}$ & level & $\mathbf{l}_{\text {geo }}$ & level & $\mathbf{I}_{\text {geo }}$ & level \\
\hline $\mathrm{Cu}$ & -0.63 & 0 & -1.57 & 0 & -1.75 & 0 & -0.28 & 0 & -1.64 & 0 & 1.27 & 1 \\
\hline $\mathrm{Zn}$ & -0.06 & 0 & -1.22 & 0 & -1.08 & 0 & -0.16 & 0 & -1.32 & 0 & 0.12 & 1 \\
\hline $\mathrm{Pb}$ & -1.27 & 0 & -2.05 & 0 & -1.12 & 0 & -1.83 & 0 & -2.45 & 0 & -0.81 & 0 \\
\hline $\mathrm{Cd}$ & -5.2 & 0 & -5.1 & 0 & -5.2 & 0 & -1.0 & 0 & -5.8 & 0 & 0.43 & 1 \\
\hline As & 3.43 & 4 & 3.38 & 4 & 3.30 & 4 & 3.27 & 4 & 3.08 & 4 & 2.92 & 3 \\
\hline
\end{tabular}

Table 3. Pearson correlation coefficients.

\begin{tabular}{|c|c|c|c|c|}
\hline & $\mathbf{C u}$ & $\mathbf{P b}$ & $\mathbf{Z n}$ & Cd \\
\hline $\mathbf{C u}$ & $\mathbf{1}$ & & & \\
\hline \hline $\mathrm{Pb}$ & 0.091 & 1 & & \\
\hline $\mathrm{Zn}$ & $0.929 * *$ & 0.362 & $0.528^{*}$ & 1 \\
\hline $\mathrm{Cd}$ & $0.787^{* *}$ & -0.166 & $0.476^{*}$ & -0.136 \\
\hline $\mathrm{As}$ & 0.271 & $0.581^{*}$ & & 1 \\
\hline
\end{tabular}

Notes: ${ }^{*} \mathrm{p}<0.05$.and $* * \mathrm{p}<0.01$. 
Table 4. Results from principal component analysis based on metals.

\begin{tabular}{|c|c|c|}
\hline Factors & Variance Explained by Components & Percentages of Total Variance Explained (\%) \\
\hline \hline 1 & 2.674 & 53.480 \\
\hline 2 & 1.668 & 86.839 \\
\hline \multicolumn{2}{|c|}{ Rotated loading matrix } \\
\hline $\mathrm{Cu}$ & 0.952 & -0.285 \\
\hline $\mathrm{Pb}$ & 0.367 & 0.790 \\
\hline $\mathrm{Zn}$ & 0.963 & 0.049 \\
\hline $\mathrm{Cd}$ & 0.674 & -0.645 \\
\hline $\mathrm{As}$ & 0.501 & 0.738 \\
\hline
\end{tabular}

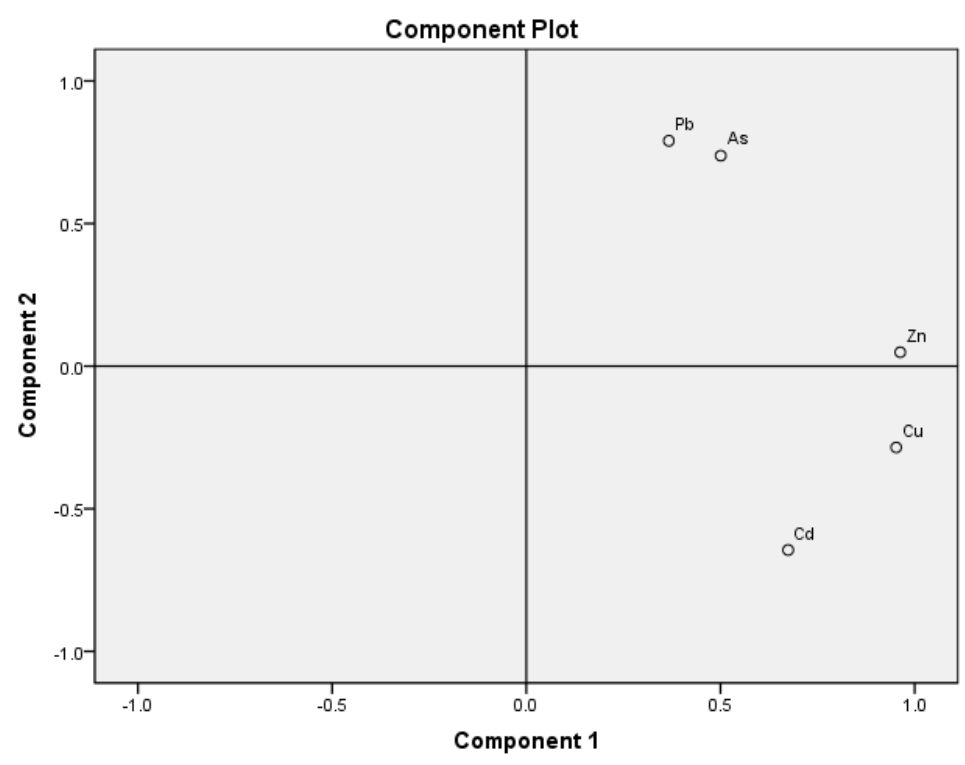

Fig. (3). The principal component analysis loading plot of selected elements.

right side of the $\mathrm{x}$-axis (Fig. 3), which contributed high positive loadings to factor 1 . The presence of $\mathrm{Cu}, \mathrm{Zn}$ and $\mathrm{Cd}$ reflected the contribution of the natural geological sources of metals (e.g. weathered bedrock and corrosion product) into the coastal sediments. The sources of $\mathrm{Pb}$ and $\mathrm{As}$ infer that it mainly originates from effluents and wastes of human activities which affect the area such as aquaculture, and combustion of gasoline and diesel fuel by ships.

\section{CONCLUSION}

In the present study, different useful tools, methods, guidelines, and indices have been employed for the evaluation of the sediment pollution from the Dongzhai Harbor. The highest values of the contamination factor (marine sediment quality guidelines), pollution load index (PLI), geoaccumulation index $\left(\mathrm{I}_{g e o}\right)$, and source factor (PCA) for all the selected metals were found in the study region. From the above results and discussion, it appears that As may occur occasional biological effect. Also, $\mathrm{I}_{\text {geo }}$ suggest there are serious pollution levels of As at all five stations. The pollution load index (PLI) and mERM-Q derived from the contamination factors shows that the potential ecological risk zone appear in northern and southern of Dongzhai Harbor. According to the factor analysis, the primary factor originates from natural sources. As and $\mathrm{Pb}$ resulted primarily from aquaculture, and combustion of gasoline and diesel fuel by ships. Numerous metals, including those elements considered highly toxic, such as $\mathrm{Cu}, \mathrm{Zn}, \mathrm{Pb}, \mathrm{Cd}$, As are stored in sediments of this mangrove ecosystem, which represents a potential ecotoxicological risk. According to guidelines previously established for the management and policy of sediment research, the development of public policy programs for restoration and recovery of natural resources, such as mangrove systems, must focus on the integration of socio-economic aspects and natural sciences. 


\section{CONFLICT OF INTEREST}

The authors confirm that this article content has no conflicts of interest.

\section{ACKNOWLEDGEMENTS}

This work was supported by the Ocean Public Welfare Scientific Research Project, State Oceanic Administration People's Republic of China (Grant No. 201105024).

\section{REFERENCES}

[1] S. Bayen, "Occurrence bioavailability and toxic effects of trace metals and organic contaminants in mangrove ecosystems: a review", Environ. Int. vol. 48, pp. 84-101, 2012.

[2] L. L. Cao, and H. T. Tian, "Multivariate Analyses and Evaluation of Heavy Metals by Chemometric BCR Sequential Extraction Method in Surface Sediments from Lingdingyang Bay, South China”, Sustainability, vol. 7, pp. 4938-4951, 2015.

[3] L. L. Cao, and C. G. Huang, "Pollution status of selected metals in surface sediments of the Pearl River Estuary and Daya Bay, South China Sea", J. Residuals Sci. Tech, vol. 11, pp. 119-130, 2014

[4] J. C. Fernández-Cadena, and S. Andrade, "Heavy metal concentration in mangrove surface sediments from the north-west coast of South America", Mar.Pollut.Bull., vol. 82, pp. 221-226, 2014.
[5] L. Hakanson, "An ecological risk index for aquatic pollution control.asedimentological approach”, Water Research vol. 14, pp. 975$1001,1980$.

[6] X. Jiang, and W. W. Wang, "Initial identification of heavy metals contamination in Taihu Lake, a eutrophic lake in China", Journal of Environmental Sciences, vol. 24, pp. 1539-1548, 2012.

[7] E. R. Long, and L. G. Morgan, "The Potential for Biological Effects Of Sediment Sorbed Contaminants Tested in the National Status and Trends Program. NOAA Technical Memorandum NOS OMA 52", National Oceanic and Atmospheric Administration. Seattle, Washington, 2010.

[8] D. Mackay, "Multimedia environmental models: the fugacity approach, 2nd ed", CRC Press, USA, 2001.

[9] Y. W. Qiu, and K. F. Yu, "Accumulation of heavy metals in sediment of mangrove wetland from Hainan Island", Journal of Tropical Oceanography, vol. 30, no. 2, pp.102-108, 2011.

[10] GB 18668-2002, "SEPA (State Environmental Protection Administration of China)". Marine Sediment Quality (). Standards Press of China, Beijing, 2002.

[11] N. F. Tam, and Y. S. Wong, "Spatial variation of heavy metals in surface sediments of Hong Kong mangrove swamps", Environ. Pollut., vol. 110, pp. 195-205, 2000.

[12] D. Tomlinson, and J. Wilson, "Problems in the assessment of heavy-metal levels in estuaries and the formation of a pollution index", Helgol. Mar. Res., vol. 33, pp. 566-575, 1980.

(C) Lu et al.; Licensee Bentham Open.

This is an open access article licensed under the terms of the Creative Commons Attribution Non-Commercial License (http://creativecommons.org/licenses/by$\mathrm{nc} / 3.0 /$ ) which permits unrestricted, non-commercial use, distribution and reproduction in any medium, provided the work is properly cited. 